\title{
Effectiveness of fibrin sealant as a hemostatic technique in accelerating endoscopic submucosal dissection-induced ulcer healing and preventing stricture in the esophagus: A retrospective study
}

\author{
JING WANG $^{1 *}$, SHAO-LEI LI ${ }^{2 *}$, NAN WU $^{2}$ and QI WU ${ }^{1}$ \\ ${ }^{1}$ Key Laboratory of Carcinogenesis and Translational Research (Ministry of Education/Beijing), \\ Endoscopy Center, Peking University Cancer Hospital and Institute; ${ }^{2}$ Key Laboratory of Carcinogenesis \\ and Translational Research (Ministry of Education/Beijing), Department of Thoracic Surgery II, \\ Peking University Cancer Hospital and Institute, Beijing 100142, P.R. China
}

Received December 10, 2019; Accepted May 21, 2020

DOI: $10.3892 / \mathrm{ol} .2020 .11777$

\begin{abstract}
The aim of the present retrospective study was to evaluate the effectiveness of conservative electrocoagulation followed by porcine fibrin sealant (FS) as a protective hemostatic technique for wounded microvessels in promoting the healing of endoscopic submucosal dissection (ESD)-induced ulcer, and preventing esophageal strictures that follow ESD. A total of 203 patients with early esophageal cancer or precancerous lesions were retrospectively analyzed. The 1-month ulcer healing and stricture rates were compared between the two groups (combined hemostats and electrocautery groups). The 1-month complete healing rate was $77.0 \%$ in the combined hemostats group and $52.6 \%$ in the electrocautery group $(\mathrm{P}=0.003)$. The use of FS and a smaller resected range $(<3 / 4$ circumference) was associated with a better 1 -month healing rate. For patients with a $\geq 3 / 4$ circumference mucosal defect, the esophageal stricture rate was $31.6 \%$ (6/19) in the combined hemostats group and $25.0 \%$ $(2 / 8)$ in the electrocautery group. There was no difference in the stricture rate $(\mathrm{P}=0.737)$ and dilation time $(\mathrm{P}=0.733)$ between the two groups. In conclusion, the application of conservative electrocoagulation followed by porcine FS as a wound-protection technique promoted ESD-induced ulcer healing in the esophagus. However, this combined hemostatic
\end{abstract}

Correspondence to: Dr Qi Wu, Key Laboratory of Carcinogenesis and Translational Research (Ministry of Education/Beijing), Endoscopy Center, Peking University Cancer Hospital and Institute, 52 Fu-Cheng Road, Haidian, Beijing 100142, P.R. China E-mail: wuqi1973@163.com

*Contributed equally

Key words: porcine fibrin sealant, ulcer, healing, stricture, dilation, endoscopic submucosal dissection, electrocoagulation technique was not superior to the conventional hemostatic method in preventing post-ESD stricture in patients with large esophageal mucosal defects.

\section{Introduction}

Endoscopic submucosal dissection (ESD) is considered an effective treatment approach for superficial esophageal squamous cell carcinoma, according to the National Comprehensive Cancer Network (NCCN) guidelines (1). As compared to the conventional endoscopic mucosal resection (EMR) technique, ESD facilitates a more precise histopathological assessment and has lower recurrence rates in patients with esophageal dysplasia (2,3). ESD-induced ulcer is one of the major factors associated with patient recovery following surgery. Faster wound healing may allow the patient to resumes a normal diet sooner and the amount of proton pump inhibitors (PPIs) required to be administered may also be lower. However, esophageal stricture following endoscopic resection caused by the healing of large mucosal defects is a major complication in such patients. To prevent postprocedural bleeding following esophageal ESD, the microvessels of the ESD bed should be coagulated using coagulation forceps after the lesion has been completely resected. Despite its effectiveness in preventing post-ESD bleeding, excess electrocoagulation is associated with poor healing of ESD-induced ulcers (4). Therefore, it is important to identify a hemostatic method to protect the microvessels and promote ESD-induced ulcer healing. Stricture rates following ESD have been reported to be $3-11.6 \%(5,6)$. Mucosal defects of $>3 / 4$ circumference have been indicated to be significantly associated with post-ESD esophageal strictures (7), markedly reducing the patients' quality of life. Stricture rates were reported to be $88 \%$ for circumferential EMR (8), while they were $>90 \%$ for ESD of $>3 / 4$ of the circumference $(9,10)$. Numerous treatments have been used as prophylaxis for post-ESD strictures (11-13), but no approach has been broadly adopted.

Several studies have evaluated the potential of fibrin sealant (FS) along with polyglycolic acid (PGA) sheets to 
prevent delayed perforation, delayed bleeding and esophageal strictures following ESD (14-18). To the best of our knowledge, no previous study has reported the use of FS as a hemostat for the rapid healing of ESD-induced ulcer in the esophagus. Furthermore, only a few studies have investigated the effectiveness of FS in preventing esophageal strictures following ESD, except for the use of fibrin glue to stick the PGA sheets to the ESD ulcer bed $(14,15,19)$. Therefore, the aim of the present retrospective study was to evaluate the effectiveness of conservative electrocoagulation followed by porcine FS as a hemostatic technique in promoting ESD-induced ulcer healing and preventing esophageal strictures following ESD.

\section{Materials and methods}

Patients. Patients with low-grade squamous cell dysplasia, high-grade neoplasia or squamous cell carcinoma of the esophagus who underwent ESD at the Peking University Cancer Hospital (Beijing, China) between January 2012 and December 2018 were included in the present study. The data were collected and reviewed retrospectively based on clinical records, images and videos of the endoscopic procedures.

The inclusion criteria were as follows: i) Age, $\geq 18$ years; ii) superficial esophageal squamous cell neoplasms $<200 \mu \mathrm{m}$ from the muscularis mucosae (SM1) or $\geq 200 \mu \mathrm{m}$ from the muscularis mucosae ( $\geq \mathrm{SM} 2$ ), as evaluated by biopsy, magnifying endo scopy with narrow-band imaging and/or endoscopic ultrasonography; iii) no history of chemotherapy or radiotherapy for esophageal cancer prior to ESD.

The exclusion criteria were as follows: i) Severe coagulation abnormalities, ii) perforation or damage of the muscle layer during ESD, which required suturing with a metal clip, iii) recurrent or new lesions adjacent to a previous ESD/EMR scar, and iv) additional surgical or radiation treatment following ESD.

Patients taking antiplatelet agents, including aspirin, were requested to stop 7 days prior to the ESD procedure and resume 7 days after ESD. Warfarin was discontinued prior to ESD and heparin was administered as a bridging therapy. Prothrombin time-international normalized ratio (PT-INR) was checked 3-4 days after stopping warfarin. Next, ESD was performed if the PT-INR was $\leq 1.5$. Warfarin was resumed $24 \mathrm{~h}$ after ESD.

This study was approved by the Ethics Committee of Peking University Cancer Hospital (Beijing, China) in accordance with the Declaration of Helsinki and written informed consent was obtained from all patients.

ESD. ESD was performed through single-channel upper gastrointestinal endoscopy (GIF Q260J; Olympus Corp.) using a high-frequency generator (VIO 200S; ERBE Elektromedizin GmbH). ENDO CUT Q (3:2:4=effect/cutting duration/cutting interval) was used for both mucosal incision and submucosal dissection. Hemostasis was achieved with FORCED COAGE2, $40 \mathrm{~W}$. Premixed sterilized solution of glycerol (10\% glycerol and 5\% fructose; Cisen Pharmaceutical, Co., Ltd.) with indigo carmine, and $2 \mathrm{ml}$ of 1:10,000 epinephrine were injected into the submucosa using an injection needle (NM-200L-0423; Olympus Corp.). The DualKnife (KD-650U; Olympus Corp.) was used to mark the lesion margin, followed by an incision and dissection of the lesion. All ESD procedures were completed by the same surgeon with an experience of $>100$ ESD cases per year, over the preceding 5 years.

ESD wound handling and postoperative management. In the electrocautery group, all visible vessels were coagulated using a hemostatic grasper (FD-410LR; Olympus Corp.) after the lesions were completely resected (Fig. 1A). In the combined hemostats group, only pulsatile vessels or vessels measuring $>0.3 \mathrm{~mm}$, which is also the diameter of the knife tip of the DualKnife, were coagulated, and microvessels measuring $<0.3 \mathrm{~mm}$ of the ESD wound were preserved (Fig. 1B). Following conservative coagulation, porcine FS (BIOSEAL; Porcine Fibrin Sealant kit; $5 \mathrm{ml}$; Guangzhou Bioseal Biotechnology Co., Ltd), which forms a gel 3-5 sec after mixing of the components of FS consisting of fibrinogen gel, lyophilized thrombin and catalyst solution of $\mathrm{CaCl}_{2}$, was sprayed onto the wound in the combined hemostats group. It took $\sim 30 \mathrm{sec}$ to spray the FS onto the ESD wound through a spray tube (Video S1).

Follow-up endoscopy was performed $24 \mathrm{~h}$ after ESD to identify any possible bleeding or perforation and analyze the preservation area of FS. All patients received an intravenous injection of PPIs within $48 \mathrm{~h}$ after ESD. Patients were prescribed a standard dose of PPIs twice a day for 8 weeks from $48 \mathrm{~h}$ post-ESD. Patients who had undergone resection of $<3 / 4$ of the esophageal circumference were followed up by EGD 1 month after ESD to identify the ulcer healing degree (Fig. 1C-H), and then every 3 months for the first year after ESD. Patients with $>3 / 4$ circumference mucosal defects received oral prednisolone, starting at $30 \mathrm{mg} /$ day from day 3 after ESD, which was gradually tapered (30, 25, 20, 15 and $10 \mathrm{mg}$ for 7 days each) and followed with a dose of $10 \mathrm{mg} /$ day until the ESD wound had healed with complete epithelialization.

During the second-look endoscopy $24 \mathrm{~h}$ after ESD for patients with a high risk of strictures ( $>3 / 4$ of the esophageal circumference resected), possible delayed bleeding and the preservation of FS was first evaluated (Fig. 2). Next, a metal guidewire was placed into the stomach through a nasal gastroscope. A 20 French silicone nasogastric tube (DRW-X; B.J. Dare Medical Equipment Co., Ltd.) was then inserted into the stomach through the metal guidewire following the withdrawal of the nasal gastroscope to prevent strictures. These patients were scheduled to return to the clinic for 20 French nasogastric tube replacement every 2-3 weeks, as it becomes stiff 2 weeks following insertion. Esophagogastroduodenoscopy (EGD) was performed every month for these patients to assess the healing states of the ESD ulcer. The tube was removed when the ESD wound had healed well with complete epithelialization, as identified by EGD.

Outcome measures. The primary endpoint was the 1-month ulcer healing rate following ESD, while secondary endpoints included delayed bleeding and esophageal stricture rates. Delayed bleeding was diagnosed on second-look endoscopy $24 \mathrm{~h}$ after ESD. Contact was maintained with the patients from the day they were discharged until 1 month after ESD, to evaluate possible delayed bleeding.

The 1-month ulcer healing rate after ESD was defined as good, moderate or poor. Good healing was defined as complete epithelialization of the wound (Fig. 1C and D), moderate healing as a lineal ulcer scar (Fig. 1E and F) and poor healing 

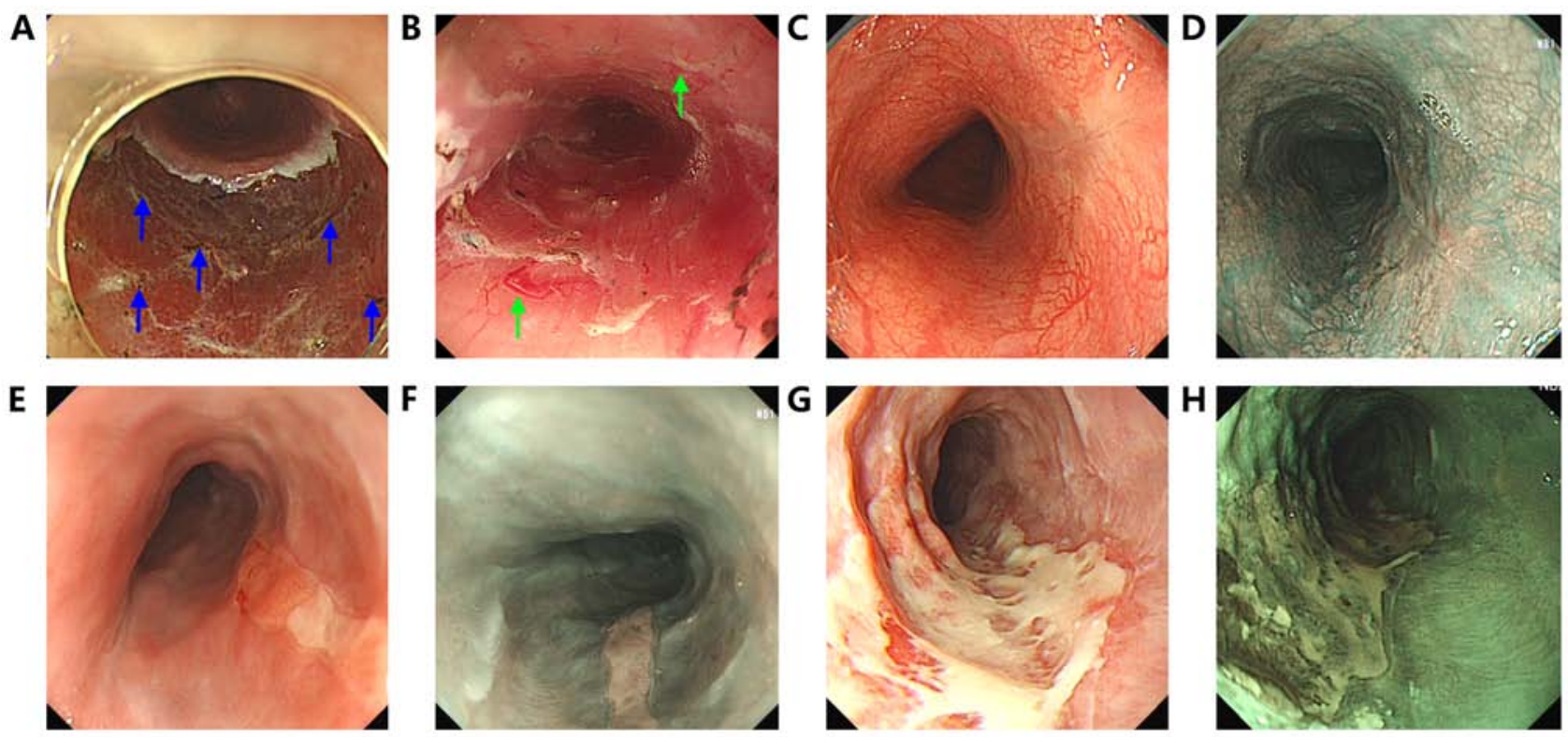

Figure 1. ESD wound management and different degrees of ulcer healing after 1 month. (A) In the electrocautery group, all visible vessels which did not receive porcine fibrin sealant were destroyed by coagulation using a hemostatic grasper. Blue arrows indicate vessels destroyed by coagulation. (B) In the combined hemostats group, microvessels (green arrows) measuring $<0.3 \mathrm{~mm}$ (diameter of the knife tip of DualKnife) in the ESD wound were preserved. (C) Complete epithelialization indicated good healing of the ESD wound on white light (the combined hemostats group). (D) Good healing of the ESD wound on NBI (the same case of image C). (E) Lineal ulcer scar exhibiting moderate healing of the ESD wound on white light (the electrocautery group). (F) Moderate healing of the ESD wound on NBI (the same case of image E). (G) Obvious ulcer with white exudate exhibited poor healing of the wound one month after ESD on white light (the electrocautery group). (H) Poor healing of the ESD wound on NBI (the same case of image G). ESD, endoscopic submucosal dissection; NBI, narrow-band imaging.
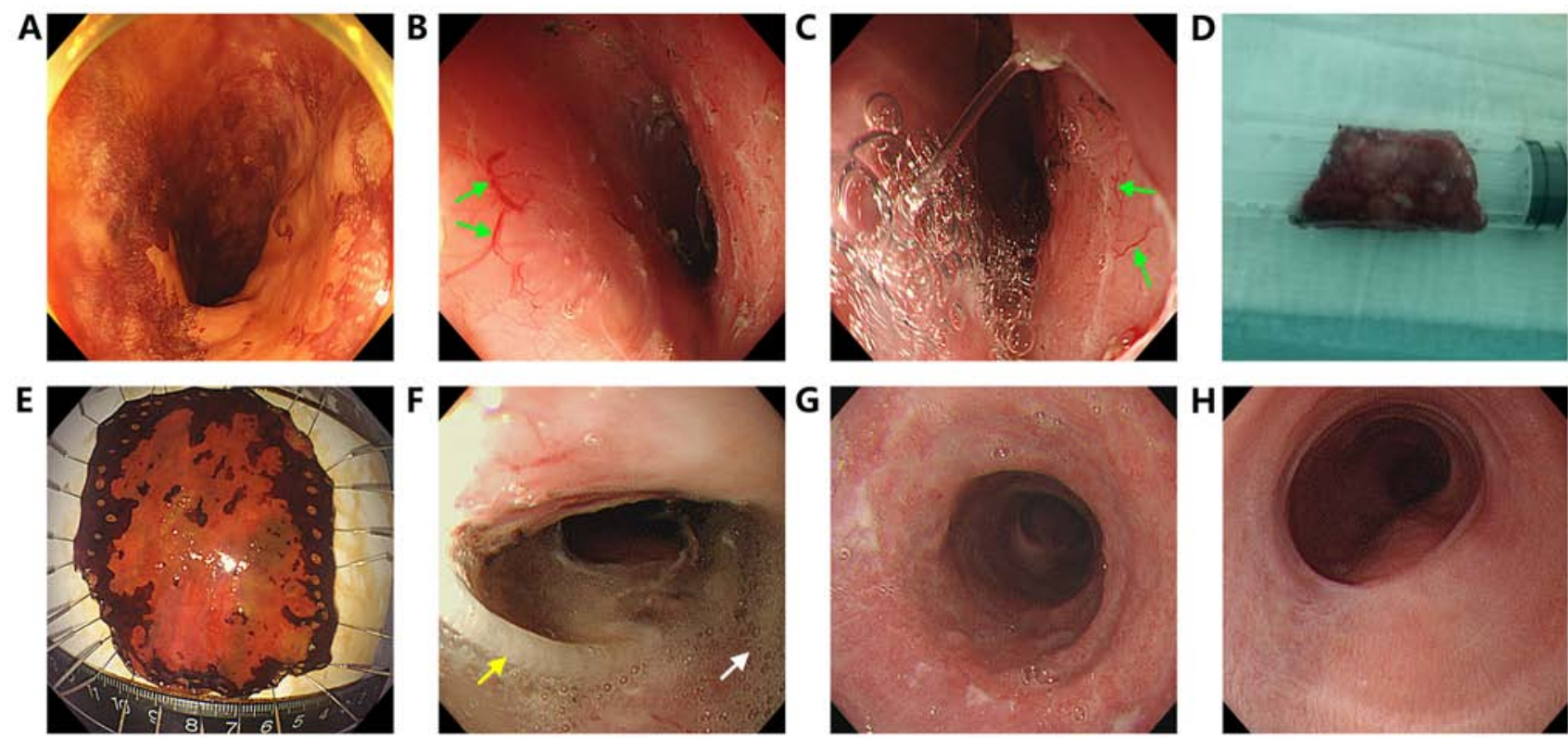

Figure 2. A representative case treated by ESD. (A) Chromoendoscopy indicated a $4 / 5$ circumferential lesion in the middle esophagus. (B) Circumferential ESD wound of intramucosal squamous cell carcinoma of the esophagus. Microvessels measuring $<0.3 \mathrm{~mm}$ were preserved (green arrows). (C) The ESD wound was sprayed with porcine FS. Green arrows indicate preserved microvessels measuring $<0.3 \mathrm{~mm}$. (D) En bloc resection was achieved. (E) The specimen was $90 \times 75 \mathrm{~mm}$ in size. Tumor map indicating the effect of spaying Lugol's iodine solution on the lesion. The scale was in mm. (F) Porcine FS, which was not easily washed away by with flushing water, was still visible on the surface of the ESD wound $24 \mathrm{~h}$ after ESD. The yellow arrow indicates the porcine FS and the white arrow indicates salivary fluid. A 20 French silicone nasogastric tube was inserted through the esophageal ESD wound into the stomach to prevent stricture (not shown). (G) At one month after ESD, most of the granulation tissue was replaced by new squamous epithelium. (H) At two months after ESD, the ESD wound was well healed with complete epithelialization. The 20 French silicone nasogastric tube was then removed. ESD, endoscopic submucosal dissection; FS, fibrin sealant.

(Fig. 1G and $\mathrm{H}$ ) as an obvious ulcer (with the ulcer crater still evident). Bleeding after ESD was divided into 3 degrees: None, minor and massive bleeding. Minor bleeding was defined as slight oozing of the ESD bed that stopped without any management or was able to be controlled by spraying hemostatic drugs during endoscopy. Massive bleeding was defined as 
active microvessel bleeding that required to be coagulated using a hemostatic grasper. The severity of dysphagia was scored as follows: Score 0, able to consume a normal diet/no dysphagia; score 1, able to swallow solid foods; score 2, able to swallow only semi-solid foods; score 3 , able to swallow liquids only; score 4, unable to swallow anything/total dysphagia. Esophageal stricture was diagnosed at a dysphagia score of $\geq 2$ and the standard diagnostic endoscopy (9.8 $\mathrm{mm}$ in diameter) was not able to pass through the stricture. Preservation of FS $24 \mathrm{~h}$ after ESD was scored as follows: None, preservation area $\leq 50 \%$ coverage of the ESD wound area, and preservation area of $>50 \%$ coverage of the ESD wound area.

The specimen was pinned onto the board after the lesion was completely removed following ESD. The specimen surface area was determined using the ellipse formula: Area $\left(\mathrm{cm}^{2}\right)=$ [shortest length $\left.(\mathrm{cm}) / 2\right] \times$ (longest length $(\mathrm{cm}) / 2$ ] $\mathrm{x} \pi$. According to the NCCN guidelines and Paris endoscopic classification of superficial neoplastic lesions $(1,20)$, differentiated-type carcinoma includes well and moderately differentiated squamous cell carcinoma, while undifferentiated-type carcinoma includes poorly differentiated and undifferentiated squamous cell carcinoma. The tumor invasion depth was classified as follows: M1, intraepithelial; M2, invasion to the lamina propria; M3, invasion to the muscularis mucosae; SM1, <200 $\mu \mathrm{m}$ from the muscularis mucosae; or $\geq \mathrm{SM} 2, \geq 200 \mu \mathrm{m}$ from the muscularis mucosae.

Statistical analysis. Continuous variables are presented as the mean \pm standard deviation. The $\chi^{2}$ test was performed to compare categorical variables, the Student's t-test was used for continuous and normally distributed variables and the Mann-Whitney U-test was used for data that were not normally distributed. The data were assessed for normality of distribution by visually checking the histogram and using the Kolmogorov-Smirnov normality test. Univariate logistic regression analysis was performed first to detect the association between FS and ulcer healing. Multivariate logistic regression analysis was then performed to examine the association between FS use and ulcer healing with adjustment for independent variables that may impact ulcer healing (including age, location, depth and resection size). $\mathrm{P}<0.05$ was considered to indicate a statistically significant difference. All statistical analyses were performed using SPSS software (version 22.0; IBM Corp.).

\section{Results}

Baseline characteristics of patients. A total of 203 patients with squamous cell low-grade dysplasia, high-grade neoplasia or squamous cell esophageal carcinoma, who underwent ESD at the Peking University Cancer Hospital (Beijing, China) between January 2012 and December 2018 were considered for the present study. Among them, 8 patients had another synchronous primary carcinoma outside the esophagus, 26 underwent resection of $\geq 2$ pieces of mucosa of multiple lesions in the esophagus at the same time, 9 had lesions at the gastroesophageal junction and underwent resection of the gastric mucosa, 3 had perforations during ESD that were treated with hemostasis clips and 7 received additional surgery or radiotherapy, as they were beyond the absolute or relative indications described, and were therefore excluded. Finally, a total of 150 patients were included in the present study. The characteristics of the patients in the electrocautery $(n=76)$ and combined hemostats $(n=74)$ groups are presented in Table I. Overall, the average age of the patients was $61.1 \pm 7.35$ (mean \pm standard deviation) years and $71.33 \%$ of them were male. A conventional hemostatic method was used in cases prior to 2016, with FS predominantly adopted since June 2016. There was no difference in patient characteristics, including gender, medical comorbidities, tumor location, tumor differentiation, invasion depth (M1-M2 vs. M3-SM1 vs. $\geq \mathrm{SM} 2$ vs. LIN) and procedure time. The combined hemostats group had a significantly bigger mean resection size and area and a larger proportion of cases with a resection range of $\geq 3 / 4$ circumference and with circumferential resection when compared with those in the control group (Table I).

Treatment outcomes. At 1 month after ESD, a significant improvement in the ulcer healing rate was observed in the combined hemostats group when compared with that in the electrocautery group (good healing, $77.0 \%$ vs. $52.6 \%$; poor healing, $9.5 \%$ vs. $15.8 \% ; \mathrm{P}=0.003$; Table II). For all patients with $<3 / 4$ circumference mucosal defects, $74.0 \%$ (91/123) of ESD wounds healed well, as determined by EGD at 1 month after ESD, and no ulcer or stricture was observed during the EGD follow-ups. In the subgroup of $<3 / 4$ circumference mucosal defects, the combined hemostats group exhibited a significant improvement in the ulcer healing rate (good healing, 94.5\% vs. $57.4 \%$; poor healing, $0.0 \%$ vs. $7.4 \%$; $\mathrm{P}<0.001$; Table III). For patients with $\geq 3 / 4$ circumference mucosal defects, the combined hemostats group also exhibited a moderate improvement in the ulcer healing rate (good healing, $26.3 \%$ vs. $12.5 \%$; poor healing, $36.8 \%$ vs. $87.5 \%$; $\mathrm{P}=0.042$; Table III). However, no significant difference was observed in the wound healing time between the two groups $(\mathrm{P}=0.333$; Table III).

The total rate of stricture was $5.3 \%(8 / 150)$ in the two groups. There was no significant difference regarding the rate of stricture between the combined hemostats group and electrocautery group ( $8.1 \%$ vs. $2.6 \%, \mathrm{P}=0.136$; Table II). No stricture occurred in patients with $<3 / 4$ circumference mucosal defects in both the porcine FS and the control groups. For patients with $\geq 3 / 4$ circumference mucosal defects, the results suggested an esophageal stricture rate of $31.6 \%(6 / 19)$ in the porcine FS group and $25.0 \%(2 / 8)$ in the electrocautery group, and the mean number of endoscopic balloon dilation (EBD) sessions required in the porcine FS group (3.3) was lower than that in the control group (7.5). However, there was no significant difference in the stricture rate $(\mathrm{P}=0.737)$ and dilation time $(\mathrm{P}=0.733$; Table III). All 6 strictures in the combined hemostats group happened after removing the nasogastric tube when the ESD wound had healed well with complete epithelialization.

The total rate of delayed bleeding was $0.7 \%$ (1/150) in both groups. Only one patient in the combined hemostats group exhibited minor delayed bleeding after $24 \mathrm{~h}$ of ESD, which stopped without any management, while no delayed bleeding was observed in the electrocautery group. There was no significant difference in the rate of delayed bleeding between the two groups ( $\mathrm{P}=0.309$; Table II). After the first EGD examination $24 \mathrm{~h}$ post-ESD, no delayed bleeding was observed in any of the 
Table I. Comparison of patient characteristics between electrocautery group and combined hemostats group.

\begin{tabular}{|c|c|c|c|}
\hline Variable & $\begin{array}{l}\text { Electrocautery } \\
\text { group } \\
(\mathrm{n}=76)\end{array}$ & $\begin{array}{c}\text { Combined } \\
\text { hemostats group } \\
(\mathrm{n}=74)\end{array}$ & P-value \\
\hline Age, years & $61.46 \pm 7.35$ & $60.85 \pm 7.4$ & 0.614 \\
\hline Sex & 0.519 & & \\
\hline Male & $56(73.7)$ & $51(68.9)$ & \\
\hline Female & $20(26.3)$ & $23(31.1)$ & \\
\hline Hypertension & $19(25.0)$ & $15(20.3)$ & 0.491 \\
\hline Diabetes & $6(7.9)$ & $4(5.4)$ & 0.543 \\
\hline Anticoagulant therapy & $2(2.6)$ & $1(1.4)$ & 0.577 \\
\hline Location & 0.693 & & \\
\hline $\mathrm{U}$ & $4(5.3)$ & $5(6.8)$ & \\
\hline M & $49(64.5)$ & $51(68.9)$ & \\
\hline $\mathrm{L}$ & $23(30.3)$ & $18(24.3)$ & \\
\hline Resection range & 0.015 & & \\
\hline$<3 / 4$ circumference & $68(89.5)$ & $55(74.3)$ & \\
\hline$\geq 3 / 4$ circumference & $8(10.5)$ & $19(25.7)$ & \\
\hline Circumferential resection & $3(3.9)$ & $10(13.5)$ & 0.037 \\
\hline Resected area $\left(\mathrm{cm}^{2}\right)$ & $10.62 \pm 9.06$ & $15.47 \pm 13.72$ & 0.019 \\
\hline Resection size (mm) & $39.4 \pm 16.5$ & $47.5 \pm 20.9$ & 0.009 \\
\hline Procedure time (min) & $90.4 \pm 44.2$ & $89.6 \pm 53.5$ & $0.492^{\mathrm{a}}$ \\
\hline Differentiation & 0.165 & & \\
\hline LIN & $12(15.8)$ & $19(25.7)$ & \\
\hline $\mathrm{D}$ & $59(77.6)$ & $47(63.5)$ & \\
\hline $\mathrm{U}$ & $5(6.6)$ & $8(10.8)$ & \\
\hline Depth & 0.950 & & \\
\hline LIN & $12(15.8)$ & $19(25.7)$ & \\
\hline M1-M2 & $45(59.2)$ & $32(43.2)$ & \\
\hline M3-SM1 & 15 (19.7) & 13 (17.6) & \\
\hline SM2-SM3 & $4(5.3)$ & $10(13.5)$ & \\
\hline
\end{tabular}

${ }^{a}$ Mann-Whitney U-test was performed, as the data did not follow a normal distribution. Values are expressed as $\mathrm{n}(\%)$ or the mean \pm standard deviation. Lower, lower third of esophagus; Middle, middle third of esophagus; Upper, upper third of esophagus; D, differentiated esophageal cancer; U, undifferentiated esophageal cancer; LIN, low-grade intraepithelial neoplasia; M1, intraepithelial carcinoma of esophagus; M2, invasion through the basement membrane of esophagus; M3, invasion to the muscularis mucosae of esophagus of esophagus; SM1, $<200$ microns from the muscularis mucosae of esophagus; $\geq$ SM2, $\geq 200$ microns from the muscularis mucosae of esophagus.

patients during follow-up. No thrombotic event was observed in the perioperative period in any of the two groups.

FS preservation rate. No significant differences in the FS preservation rate at $24 \mathrm{~h}$ post-ESD were observed among different locations and between different resection ranges (Table SI).

Ulcer healing rate. Univariate logistic regression analysis suggested that the use of FS [odds ratio $(\mathrm{OR})=3.018,95 \% \mathrm{CI}$ : 1.492-6.103, $\mathrm{P}<0.05]$ and $<3 / 4$ circumference esophageal resection $(\mathrm{OR}=9.953,95 \% \mathrm{CI}: 3.688-26.858, \mathrm{P}<0.05)$ were associated with a good 1-month healing rate (Table SII). Subgroup univariate regression analysis indicated that the use of FS was significantly associated with a good 1-month healing rate $(\mathrm{OR}=12.889,95 \% \mathrm{CI}: 3.659-45.398)$ in patients with a resection range of $<3 / 4$ circumference, while no such association was obtained in patients with a resection range of $\geq 3 / 4$ circumference ( $O R=2.450,95 \%$ CI: $0.243-25.717$; Table SII). Multivariate regression analysis was conducted to explore whether FS was also associated with good healing with control of multiple factors. The results suggested that the use of FS promoted ulcer healing in the small resection range subgroup $(<3 / 4$ circumference; $\mathrm{OR}=54.446,95 \% \mathrm{CI}$ : $8.762-338.334, \mathrm{P}<0.001)$ but had no significant impact in the large resection range subgroup ( $\geq 3 / 4$ circumference) (Table IV). In addition, multivariate analysis in the small resection range subgroup ( $<3 / 4$ circumference) also suggested that a larger size was associated with a worse healing rate $(\mathrm{OR}=0.326,95 \% \mathrm{CI}$ : $0.123-0.861, \mathrm{P}=0.024$; Table IV). 
Table II. Treatment outcomes of ulcer healing, bleeding and stricture.

\begin{tabular}{lccc}
\hline Outcome & $\begin{array}{c}\text { Electrocautery } \\
\text { group } \\
(\mathrm{n}=76)\end{array}$ & $\begin{array}{c}\text { Combined } \\
\text { hemostats } \\
\text { group } \\
(\mathrm{n}=74)\end{array}$ & P-value \\
\hline One-month healing & $12(15.8)$ & $7(9.5)$ & $0.003^{\mathrm{a}}$ \\
$\begin{array}{l}\text { Poor } \\
\text { Moderate }\end{array}$ & $24(31.6)$ & $10(13.5)$ & \\
Good & $40(52.6)$ & $57(77.0)$ & \\
Delayed bleeding & $0(0)$ & $1(1.4)$ & 0.309 \\
Stricture & $2(2.60)$ & $6(8.10)$ & 0.136 \\
\hline
\end{tabular}

${ }^{\mathrm{a}}$ Mann-Whitney U test, as the data did not follow a normal distribution. Values are expressed as n (\%).

Esophageal stricture. Univariate analysis suggested that FS was not significantly associated with stricture $(\mathrm{OR}=3.265$, 95\% CI: 0.637-16.726, P>0.05; Table SIII), but the larger resection range ( $\geq 3 / 4$ circumference) was, since patients who developed stricture all presented with a larger resection range ( $\geq 3 / 4$ circumference). Multivariate regression analysis for all patients indicated that circumferential resection was associated with stricture (OR=13.707, 95\% CI: 2.504-75.024, $\mathrm{P}=0.003$; Table SIV). For patients with $\geq 3 / 4$ circumference, the 1-month ulcer healing outcome after ESD exhibited no difference between the stricture group and non-stricture group ( $\mathrm{P}=0.954$; Table $\mathrm{SV})$.

\section{Discussion}

Despite the rapid developments of endoscopic therapy, there remains an increase in the number of patients with superficial esophageal squamous cell carcinoma undergoing ESD. Animal esophagus models have revealed 3 phases of healing and stricture formation following injury or endoscopic resection of the esophageal mucosa $(21,22)$. The first phase involves inflammatory response in the epithelium due to defect and exposure of the submucosal tissues. The second phase involves proliferation of the epithelium, starting from the edge of the mucosal defect. The third phase involves scar tissue formation. The role of angiogenesis of capillary vessels and preservation of submucosal glands in esophageal tissue regeneration has been demonstrated in animal models (21) and histological patterns of post-endoscopic esophageal healing (23). A previous study by our group indicated that preserving wound microvessels and residual submucosal tissue, including submucosal glands, by conservative electrocoagulation followed by spraying porcine FS, promoted ESD-induced ulcer healing in human stomachs (24). In the present study, a similar method was adopted to protect the wound microvessels and residual submucosal tissue following esophageal ESD. The results confirmed the effectiveness of conservative electrocoagulation followed by spraying porcine FS in accelerating the ulcer healing rate in both small ( $>3 / 4$ of the esophageal circumference) and large ESD wounds ( $>3 / 4$ of the esophageal circumference). In addition, the delayed bleeding rate did not increase, even when wound microvessels were preserved.

The occurrence of delayed bleeding following esophagus ESD was reported to be low $(2,9,25)$. Furthermore, most of the delayed bleeding of upper gastrointestinal ESD occurred within 14 days from surgery, even in patients receiving antithrombotic treatment $(26,27)$. Inhibition of gastric acid secretion by the administration of PPIs has been proved effective in reducing the bleeding rate after ESD in the stomach (28). In addition, bleeding after ESD in the esophagus was reported to be linked to no use of antisecretory medications (29). A previous study by our group suggested that using porcine FS following preservation of wound microvessels did not increase the bleeding rate after gastric ESD (24). Therefore, in the present study, porcine FS was sprayed onto the ESD wound in the combined hemostats group, as it was expected to be able to protect the preserved blood vessels from potential erosion caused by gastric acid during the early post-ESD period. In the present study, only 1 patient in the combined hemostats group exhibited minor delayed bleeding $24 \mathrm{~h}$ after ESD. Considering the potential occurrence of bleeding $24 \mathrm{~h}$ after ESD, particularly in patients resuming aspirin or warfarin treatment following ESD, contact was maintained with the patients until 1 month after ESD to evaluate possible delayed bleeding. Only 3 patients in the study had a history of taking aspirin and none of those 3 exhibited delayed bleeding after ESD. Larger-sample studies are required to explore the delayed bleeding rate for patients resuming aspirin or warfarin treatment following ESD.

ESD resection of large lesions includes the resection of $>3 / 4$ of the circumference of the esophageal lumen. However, one of the major complications of ESD for large lesions is the greater tendency of developing post-ESD cicatricial strictures. Patients suffering from esophageal stricture require repeated endoscopic dilations, such as EBD or bougie dilation, for a long period of time, if the stricture is refractory due to extended mucosal defects $(30,31)$. In addition to the increased risk of bleeding or esophageal perforation, multiple sessions of endoscopic dilation may cause adversities and discomfort in patients (31).

To date, four approaches have been used for the prevention of esophageal strictures following endoscopic resection, namely the protective, regenerative, anti-proliferative and mechanical approaches (32). In the present study, three different approaches were used at the same time to prevent esophageal stricture following ESD: Conservative electrocoagulation followed by porcine FS as a protective approach, oral administration of prednisolone as an anti-proliferative approach and placement of a 20 French nasogastric tube as a mechanical approach.

Several studies have evaluated the effectiveness of PGA sheets, esophageal covered metal stents or the combined application of both. The esophageal stricture rates were reported to be $18-57.5 \%$ (33-36). However, these approaches have major limitations, including early stent migration, cost, complexity of the procedures and requirement of a high degree of expertise. The 20 French nasogastric tube used as a mechanical approach was low-cost and easy to place and maintain in position, and yet this method has 
Table III. Healing parameters and stricture rate for different resection ranges.

\begin{tabular}{|c|c|c|c|c|c|c|}
\hline \multirow[b]{2}{*}{ Outcome } & \multicolumn{3}{|c|}{$<3 / 4$ circumference } & \multicolumn{3}{|c|}{$\geq 3 / 4$ circumference } \\
\hline & $\begin{array}{l}\text { Electrocautery } \\
\text { group }(n=68)\end{array}$ & $\begin{array}{c}\text { Combined } \\
\text { hemostats } \\
\text { group }(n=55)\end{array}$ & P-value & $\begin{array}{l}\text { Electrocautery } \\
\text { group }(n=8)\end{array}$ & $\begin{array}{c}\text { Combined } \\
\text { hemostats } \\
\text { group }(n=19)\end{array}$ & P-value \\
\hline One-month healing & & & $<0.001$ & & & 0.042 \\
\hline Poor & $5(7.4)$ & $0(0)$ & & $7(87.5)$ & $7(36.8)$ & \\
\hline Moderate & $24(35.3)$ & $3(5.5)$ & & $0(0)$ & $7(36.8)$ & \\
\hline Good & $39(57.4)$ & $52(94.5)$ & & $1(12.5)$ & $5(26.3)$ & \\
\hline Healing time (days) & NA & NA & & $58.9 \pm 21.3$ & $91.63 \pm 65.9$ & $0.333^{\mathrm{a}}$ \\
\hline Stricture & 0 & 0 & & $2(25.0)$ & $6(31.6)$ & 0.737 \\
\hline Dilation times & 0 & 0 & & $7.5 \pm 9.19$ & $3.3 \pm 3.01$ & 0.733 \\
\hline
\end{tabular}

${ }^{a}$ Mann-Whitney U-test, as the data did not follow a normal distribution. Values are expressed as $\mathrm{n}(\%)$ or the mean \pm standard deviation. NA, not available.

Table IV. Multivariate regression analysis for ulcer healing for different resection ranges.

\begin{tabular}{|c|c|c|c|c|c|c|}
\hline \multirow[b]{2}{*}{ Variable } & \multicolumn{3}{|c|}{$<3 / 4$ circumference } & \multicolumn{3}{|c|}{$3 / 4$ circumference } \\
\hline & OR & $95 \% \mathrm{CI}$ & P-value & OR & $95 \% \mathrm{CI}$ & P-value \\
\hline Use of FS & 54.446 & $8.762-3.383 \times 10^{2}$ & $<0.001$ & 3.077 & $0.054-1.738 \times 10^{2}$ & 0.585 \\
\hline Age, continuous & 0.945 & $0.870-1.026$ & 0.179 & 1.312 & $0.909-1.893$ & 0.147 \\
\hline Location & & & & & & 0.406 \\
\hline Middle vs. lower & 1.032 & $0.296-3.596$ & 0.961 & $2.254 \times 10^{3}$ & $0.018-2.854 \times 10^{8}$ & 0.198 \\
\hline Upper vs. lower & $5.640 \times 10^{8}$ & NA & 0.999 & 20.666 & $0.004-1.141 \times 10^{5}$ & 0.491 \\
\hline Depth & & & 0.418 & & & 0.773 \\
\hline M1-M2 vs. LIN & 0.102 & $0.007-1.549$ & 0.100 & 0.6 & $0.007-48.453$ & 0.819 \\
\hline M3-SM1 vs. LIN & 0.092 & $0.005-1.757$ & 0.113 & 0.911 & $0.003-2.639 \times 10^{2}$ & 0.974 \\
\hline SM2-SM3 vs. LIN & 0.109 & $0.004-2.823$ & 0.182 & 0.046 & $0.00006-33.794$ & 0.361 \\
\hline Resection size, continuous & 0.326 & $0.123-0.861$ & 0.024 & 3.198 & $0.518-19.733$ & 0.211 \\
\hline
\end{tabular}

OR, odds ratio; Lower, lower third of esophagus; Middle, middle third of esophagus; Upper, upper third of esophagus; LIN, low-grade intraepithelial neoplasia; M1, intraepithelial carcinoma of esophagus; M2, invasion through the basement membrane of esophagus; M3, invasion to the muscularis mucosae of esophagus of esophagus; SM1, $<200$ microns from the muscularis mucosae of esophagus; $\geq$ SM2, $\geq 200$ microns from the muscularis mucosae of esophagus; FS, fibrin sealant; NA, not available.

not been reported previously. The silicone material of the nasogastric tube was of sufficient softness and the 20 French was not the largest in diameter but was considered the most tolerable tube size for patients after trying different ones. For the patients who underwent resection of $\geq 3 / 4$ of the circumference of the esophagus, a 20 French silicone nasogastric tube was placed through the esophageal ESD wound into the stomach, replaced by a new nasogastric tube every 2 to 3 weeks and removed when the ESD wound had healed well with complete epithelialization, as determined by EGD. During follow-up, no stricture was observed by the monthly EGD examination. However, all strictures occurred in $<14$ days after the removal of the nasogastric tube, when the ESD wound had healed well with complete epithelialization. It was hypothesized that the 20 French nasogastric tube may have been efficient as a mechanical approach to prevent esophageal stricture by mechanically maintaining the diameter of the esophageal cavity no less than that of the nasogastric tube during wound healing of ESD.

Oral prednisolone was used as an anti-proliferative approach, as it was low-cost and readily available. Although endoscopic local steroid injection (ELSI) for mucosal defects has now become a standard treatment in Japan, it is associated with serious procedure-associated complications, such as bleeding or esophageal perforation $(37,38)$. A multicenter, prospective, randomized controlled phase III trial (JCOG1217) is ongoing in Japan to confirm the superiority of prophylactic 
oral steroid administration following ESD to ELSI, in terms of stricture-free survival of patients with superficial esophageal cancer (39).

In the present study, the total stricture rate in patients with $\geq 3 / 4$ circumference mucosal defects was $29.6 \%(8 / 27)$. Neither treatment of the two groups increased in stenosis when compared with the 15.3-37.5\% stenosis rate reported in the literature (32). However, the additional use of FS did not provide any benefit over the application of oral administration of prednisolone and placement of a 20 French nasogastric tube in terms of reducing the stricture rate and the number of required EBD sessions in large mucosal defects $(\geq 3 / 4$ circumference). This negative result may be due to the fact that the average size of the resection was larger and there were more circumferential resection cases in the combined hemostats than in the control group.

However, the present study was not without its limitations. First, it was a single-center, retrospective analysis and the sample size was small. Further multicenter randomized controlled trials involving more patients with mucosal defects covering $>3 / 4$ of the circumference are required to confirm the effectiveness of porcine FS in preventing strictures. In addition, the present study provided no direct evidence that porcine FS protected the blood vessels from gastric acid erosion. As suggested by previous studies, the mechanism of porcine FS to prevent bleeding after gastric ESD may be to separate the ulcer bed to the gastric acid and bile $(24,40)$. In addition, non-use of PPIs was associated with bleeding after esophageal ESD (29). Finally, no histological investigation of the mechanism of preventing esophageal stricture was performed in the present study. Therefore, it is also necessary to investigate whether it is the FS, prednisolone, silicone nasogastric tube or a synergistic effect of the 3 methods that produced efficacious results.

In conclusion, the application of conservative electrocoagulation followed by porcine FS as a wound-protective technique promoted ESD-induced ulcer healing of the esophagus in a relatively small resection range $(<3 / 4$ circumference). However, this combined hemostats technique was not superior in preventing post-ESD strictures in patients with large esophageal mucosal defects.

\section{Acknowledgements}

The authors thank Dr Dongfeng Niu and Dr Li Zhang [Key Laboratory of Carcinogenesis and Translational Research (Ministry of Education/Beijing), Department of Pathology, Peking University Cancer Hospital and Institute, Beijing, China] for their help as pathologists.

\section{Funding}

This study was supported by the National Key R\&D Program of China (grant no. 2018YFC0910700).

\section{Availability of data and materials}

The datasets used and analyzed during the present study are available from the corresponding author on reasonable request.

\section{Authors' contributions}

QW conceived and designed the study. JW and SLL analyzed and interpreted the data. JW drafted the manuscript. NW helped to perform the analysis and critically revised the article for important intellectual content. All authors read and approved the final manuscript.

\section{Ethics approval and consent to participate}

This study was authorized by the Beijing Cancer Hospital Research Ethics Committee (Beijing, China; no. 2017YJZ39) and the study was performed in accordance with the Declaration of Helsinki. All patients or their families provided written informed consent.

\section{Patient consent for publication}

Not applicable.

\section{Competing interests}

All authors declare that they have no competing interests.

\section{References}

1. Network NCC: (NCCN) Clinical Practice Guidelines in Oncology. Esophageal and Esophagogastric Junction Cancers, Version 2. 2020.

2. Tsujii Y, Nishida T, Nishiyama O, Yamamoto $K$, Kawai N, Yamaguchi S, Yamada T, Yoshio T, Kitamura S, Nakamura T, et al: Clinical outcomes of endoscopic submucosal dissection for superficial esophageal neoplasms: A multicenter retrospective cohort study. Endoscopy 47: 775-783, 2015.

3. Yamashina T, Ishihara R, Nagai K, Matsuura N, Matsui $F$, Ito T, Fujii M, Yamamoto S, Hanaoka N, Takeuchi Y, et al: Long-term outcome and metastatic risk after endoscopic resection of superficial esophageal squamous cell carcinoma. Am J Gastroenterol 108: 544-551, 2013.

4. Horikawa Y, Mimori N, Mizutamari H, Kato Y, Shimazu K, Sawaguchi M, Tawaraya S, Igarashi K and Okubo S: Proper muscle layer damage affects ulcer healing after gastric endoscopic submucosal dissection. Dig Endos 27: 748-754, 2015.

5. Takahashi H, Arimura Y, Masao H, Okahara S, Tanuma $\mathrm{T}$, Kodaira J, Kagaya H, Shimizu Y, Hokari K, Tsukagoshi H, et al: Endoscopic submucosal dissection is superior to conventional endoscopic resection as a curative treatment for early squamous cell carcinoma of the esophagus (with video). Gastrointest Endos 72: 255-264, 264.e1-e2, 2010.

6. Kim JS, Kim BW and Shin IS: Efficacy and safety of endoscopic submucosal dissection for superficial squamous esophageal neoplasia: A meta-analysis. Dig Dis Sci 59: 1862-1869, 2014.

7. Miwata T, Oka S, Tanaka S, Kagemoto K, Sanomura Y, Urabe Y, Hiyama T and Chayama K: Risk factors for esophageal stenosis after entire circumferential endoscopic submucosal dissection for superficial esophageal squamous cell carcinoma. Surg Endos 30: 4049-4056, 2016.

8. van Vilsteren FG, Pouw RE, Seewald S, Alvarez Herrero L, Sondermeijer CM, Visser M, Ten Kate FJ, Yu Kim, Teng KC, Soehendra N, Rösch T, et al: Stepwise radical endoscopic resection versus radiofrequency ablation for Barrett's oesophagus with high-grade dysplasia or early cancer: A multicentre randomised trial. Gut 60: 765-773, 2011.

9. Ono S, Fujishiro M, Niimi K, Goto O, Kodashima S, Yamamichi N and Omata M: Long-term outcomes of endoscopic submucosal dissection for superficial esophageal squamous cell neoplasms. Gastrointest Endos 70: 860-866, 2009.

10. Shi Q, Ju H, Yao LQ, Zhou PH, Xu MD, Chen T, Zhou JM, Chen TY and Zhong YS: Risk factors for postoperative stricture after endoscopic submucosal dissection for superficial esophageal carcinoma. Endoscopy 46: 640-644, 2014.

11. Tsuji Y, Sakaguchi Y, Fujishiro M and Koike K: Preventive measures against stricture after esophageal endoscopic submucosal dissection: Halfway through the journey to the best method. Dig Endosc 30: 600-601, 2018. 
12. Abe S, Iyer PG, Oda I, Kanai N and Saito Y: Approaches for stricture prevention after esophageal endoscopic resection. Gastrointest Endosc 86: 779-791, 2017.

13. Chai NL, Feng J, Li LS, Liu SZ, Du C, Zhang Q and Linghu EQ Effect of polyglycolic acid sheet plus esophageal stent placement in preventing esophageal stricture after endoscopic submucosal dissection in patients with early-stage esophageal cancer: A randomized, controlled trial. World J Gastroenterol 24: 1046-1055, 2018.

14. Iizuka T, Kikuchi D, Yamada A, Hoteya S, Kajiyama Y and Kaise M: Polyglycolic acid sheet application to prevent esophageal stricture after endoscopic submucosal dissection for esophageal squamous cell carcinoma. Endoscopy 47: 341-344, 2015.

15. Sakaguchi Y, Tsuji Y, Ono S, Saito I, Kataoka Y, Takahashi Y, Nakayama C, Shichijo S, Matsuda R, Minatsuki C, et al: Polyglycolic acid sheets with fibrin glue can prevent esophageal stricture after endoscopic submucosal dissection. Endoscopy 47: 336-340, 2015

16. Tsuji Y, Ohata K, Gunji T, Shozushima M, Hamanaka J, Ohno A, Ito T, Yamamichi N, Fujishiro M, Matsuhashi N and Koike K Endoscopic tissue shielding method with polyglycolic acid sheets and fibrin glue to cover wounds after colorectal endoscopic submucosal dissection (with video). Gastrointest Endosc 79: 151-155, 2014.

17. Takimoto K, Imai $\mathrm{Y}$ and Matsuyama K: Endoscopic tissue shielding method with polyglycolic acid sheets and fibrin glue to prevent delayed perforation after duodenal endoscopic submucosal dissection. Digestive Endosc 26: 46-49, 2014.

18. Kikuchi D, Iizuka T, Nomura K, Kuribayashi Y, Tanaka M, Yamashita S, Furuhata T, Matsui A, Mitani T, Makino S and Hoteya S: Feasibility of autologous fibrin glue and polyglycolic acid sheets to prevent delayed bleeding after endoscopic submucosal dissection of gastric neoplasms in patients receiving antithrombotic therapy. Gastroenterol Res Pract 2018: 2174957, 2018.

19. Kim YJ, Park JC, Chung H, Shin SK, Lee SK and Lee YC: Polyglycolic acid sheet application to prevent esophageal stricture after endoscopic submucosal dissection for recurrent esophageal cancer. Endoscopy 48: E319-E320, 2016.

20. Endoscopic Classification Review Group: Update on the paris classification of superficial neoplastic lesions in the digestive tract. Endoscopy 37: 570-578, 2005.

21. Honda M, Nakamura T, Hori Y, Shionoya Y, Nakada A, Sato T, Yamamoto K, Kobayashi T, Shimada H, Kida N, et al: Process of healing of mucosal defects in the esophagus after endoscopic mucosal resection: Histological evaluation in a dog model. Endoscopy 42: 1092-1095, 2010.

22. Nonaka K, Miyazawa M, Ban S, Aikawa M, Akimoto N, Koyama I and Kita H: Different healing process of esophageal large mucosal defects by endoscopic mucosal dissection between with and without steroid injection in an animal model. BMC Gastroenterol 13: 72, 2013.

23. Coad RA, Woodman AC, Warner PJ, Barr H, Wright NA and Shepherd NA: On the histogenesis of Barrett's oesophagus and its associated squamous islands: A three-dimensional study of their morphological relationship with native oesophageal gland ducts. J Pathol 206: 388-394, 2005.

24. Wang J, Wu Q, Yan Y, Li SJ, Yuan P, Cao CQ, Niu DF, Li ZY, $\mathrm{Bu} \mathrm{ZD}$ and Ji JF: Effectiveness of fibrin sealant as hemostatic technique in accelerating ESD-induced ulcer healing: A retrospective study. Surg Endosc 34: 1191-1199, 2020.

25. Isomoto H, Yamaguchi N, Minami H and Nakao K: Management of complications associated with endoscopic submucosal dissection/endoscopic mucosal resection for esophageal cancer. Dig Endosc 25 (Suppl 1): S29-S38, 2013.

26. Koh R, Hirasawa K, Yahara S, Oka H, Sugimori K, Morimoto M, Numata K, Kokawa A, Sasaki T, Nozawa A, et al: Antithrombotic drugs are risk factors for delayed postoperative bleeding after endoscopic submucosal dissection for gastric neoplasms. Gastrointest Endosc 78: 476-483, 2013

27. Yamamoto Y, Kikuchi D, Nagami Y, Nonaka K, Tsuji Y, Fujimoto A, Sanomura Y, Tanaka K, Abe S, Zhang S, et al: Management of adverse events related to endoscopic resection of upper gastrointestinal neoplasms: Review of the literature and recommendations from experts. Dig Endosc 31 (Suppl 1): S4-S20, 2019.
28. Uedo N, Takeuchi Y, Yamada T, Ishihara R, Ogiyama H, Yamamoto S, Kato M, Tatsumi K, Masuda E, Tamai C, et al: Effect of a proton pump inhibitor or an H2-receptor antagonist on prevention of bleeding from ulcer after endoscopic submucosal dissection of early gastric cancer: A prospective randomized controlled trial. Am J Gastroenterol 102: 1610-1616, 2007

29. Kakushima N, Hori K, Ono H, Horimatsu T, Uedo N, Ohata K, Doyama H, Kaneko K, Oda I, Hikichi T, et al: Proton pump inhibitor after endoscopic resection for esophageal squamous cell cancer: Multicenter prospective randomized controlled trial. J Gastroenterol 51: 104-111, 2016.

30. Takahashi H, Arimura Y, Okahara S, Uchida S, Ishigaki S, Tsukagoshi H, Shinomura Y and Hosokawa M: Risk of perforation during dilation for esophageal strictures after endoscopic resection in patients with early squamous cell carcinoma. Endoscopy 43: 184-189, 2011

31. Yoda Y, Yano T, Kaneko K, Tsuruta S, Oono Y, Kojima T, Minashi K, Ikematsu $\mathrm{H}$ and Ohtsu A: Endoscopic balloon dilatation for benign fibrotic strictures after curative nonsurgical treatment for esophageal cancer. Surg Endosc 26: 2877-2883, 2012.

32. Barret M, Beye B, Leblanc S, Beuvon F, Chaussade S, Batteux F and Prat F: Systematic review: The prevention of oesophageal stricture after endoscopic resection. Aliment Pharmacol Ther 42: 20-39, 2015

33. Holt BA, Jayasekeran V, Williams SJ, Lee EY, Bahin FF, Sonson R, Lord RV and Bourke MJ: Early metal stent insertion fails to prevent stricturing after single-stage complete Barrett's excision for high-grade dysplasia and early cancer. Gastrointest Endosc 81: 857-864, 2015.

34. Bhat YM, Kane SD, Shah JN, Hamerski CM and Binmoeller KF: Single-session circumferential EMR and metal stent placement for the treatment of long-segment Barrett's esophagus with high-grade intraepithelial neoplasia. Gastrointest Endosc 80: 331, 2014.

35. Wen J, Lu Z, Yang Y, Liu Q, Yang J, Wang S, Wang X, Du H, Meng J, Wang $\mathrm{H}$ and Linghu E: Preventing stricture formation by covered esophageal stent placement after endoscopic submucosal dissection for early esophageal cancer. Dig Dis Sci 59: 658-663, 2014.

36. Li L, Linghu E, Chai N, Li Z, Zou J, Du C, Wang X and Xiang J: Efficacy of triamcinolone-soaked polyglycolic acid sheet plus fully covered metal stent for preventing stricture formation after large esophageal endoscopic submucosal dissection. Dis Esophagus: 32, 2019 doi: 10.1093/dote/doy121.

37. Hanaoka N, Ishihara R, Takeuchi Y, Uedo N, Higashino K, Ohta T, Kanzaki H, Hanafusa M, Nagai K, Matsui F, et al: Intralesional steroid injection to prevent stricture after endoscopic submucosal dissection for esophageal cancer: A controlled prospective study. Endoscopy 44: 1007-1011, 2012.

38. Rajan E, Gostout C, Feitoza A, Herman L, Knipschield M, Burgart L, Chung S, Cotton P, Hawes R, Kalloo A, et al: Widespread endoscopic mucosal resection of the esophagus with strategies for stricture prevention: A preclinical study. Endoscopy 37: 1111-1115, 2005.

39. Mizutani T, Tanaka M, Eba J, Mizusawa J, Fukuda H, Hanaoka N, Takeuchi M, Aoyama I, Kojima T, Takizawa K, et al: A Phase III study of oral steroid administration versus local steroid injection therapy for the prevention of esophageal stricture after endoscopic submucosal dissection (JCOG1217, Steroid EESD P3). Jpn J Clin Oncol 45: 1087-1090, 2015.

40. ASGE Technology Committee; Bhat YM, Banerjee S, Barth BA, Chauhan SS, Gottlieb KT, Konda V, Maple JT, Murad FM, Pfau PR, et al: Tissue adhesives: Cyanoacrylate glue and fibrin sealant. Gastrointest Endosc 78: 209-215, 2013.

This work is licensed under a Creative Commons Attribution-NonCommercial-NoDerivatives 4.0 International (CC BY-NC-ND 4.0) License. 